\title{
PENGATURAN STANDARISASI PRODUK DI INDONESIA DITINJAU DARI KETENTUAN TECHNICAL BARRIERS TO TRADE AGREEMENT
}

\author{
Satria Sukananda \\ Program Pasca Sarjana Fakultas Hukum Universitas Islam Indonesia \\ Jl. Cik Di Tiro No.1, Terban, Gondokusuman, Kota Yogyakarta, Daerah Istimewa \\ Yogyakarta 55223, Indonesia \\ email: artisukananda@gmail.com
}

\begin{abstract}
Indonesia is one of World Trade Organization's member and therefore should conform to the mutilateral agreements relating to international trade including the Technical Barriers to Trade (TBT) Agreement. The TBT terms includes three concepts namely technical regulation, standard and procedures for assessment adjustment which apply to all products. The standardization has the tendency of being protective and is supposed to benefit the nation's interest, however, at the same time potentially obstructs exports from Indonesia's trading partners. On the other hand, when the standardization is implemented, the flow of products and services might threaten people's interests. The issues being addresed by this study is how to regulate and implement product standardization in Indonesia looking from the perspectives of Technical Barriers to Trade (TBT) Agreement, the formulation of Indonesian National Standards (SNI), and the establishment of SNI as obligatory standards for all. This study adopts normative law with statue approach. The legal materials are drawn from Law-related and non-Lawrelated materials which will be analysed prescriptively using deductive method. Th results of the study signify that the arrangement of TBT agreement in Indonesia will be regulated through UU No 20 Year 2014 on Standardization and Assessment Adjustment. This will be applied voluntarily or obligatory. The standardization implementation as obligatory might apply when it is related to the general ineterests, national security, national economic development, and the conservation of the environment. The effort in minimising any obstruction in trades will work effectively provided each country implement the obligatory standardization and apply Good Regulatory Practices followed by providing strandardization notification in accordance with the TBT Agreement.
\end{abstract}

Keywords : Product Standardization, Technical Barrier to Trade Agreement, Good Regulatory Practices.

\begin{abstract}
ABSTRAK
Indonesia sebagai negara anggota World Trade Organization terikat untuk tunduk pada persetujuan-persetujuan multilateral terkait perdagangan internasional termasuk tentang Technical Barriers to Trade (TBT) Agreement. teknis Ketentuan TBT Agreement bekerja melalui tiga konsep yaitu regulasi teknis, standar dan prosedur penilaian kesesuaian dan berlaku untuk semua produk. Standardisasi yang cenderung protektif dapat diterapkan
\end{abstract}

${ }^{1}$ Submission : 15 - 12 - 2018 I Review - 1: 25 - 12 - 2018 I Review - 2: $28-2$ - 2019 I Production : 1 - 3- 2019 
untuk melindungi kepentingan nasional, namun menghambat ekspor Negara-Negara mitra dagang ke Indonesia. Begitu pula sebaliknya, jika program standardisasi diterapkan, aliran barang dan jasa impor akan mengancam kepentingan umum. Rumusan masalah penelitian ini yaitu bagaimana pengaturan dan penerapan standardisasi produk di Indonesia di tinjau dari ketentuan Technical Barriers to Trade (TBT) Agreement serta bagaimana perumusan Standar Nasional Indonesia dan penetapan standar nasional secara wajib. Kajian ini menggunakan metode penelitian hukum normatif pendekatan Perundang-undangan (statue approach). Untuk bahan hukum, penelitian ini menggunakan bahan hukum dan bahan non hukum yang diperoleh dalam penelitian ini akan dianalisis secara preskriptif dengan metode deduktif. Hasil penelitian menunjukkan bahwa pengaturan akan TBT Agreement di Indonesia dituangkan melalui Undang-Undang Nomor 20 Tahun 2014 tentang Standarisasi dan Penilaian Kesesuaian. Penerapan akan standarisasi produk di Indonesia dapat dilakukan secara sukarela maupun wajib. Penerapan Standarisasi secara wajib dapat dilakukan jika menyangkut keperluan melindungi kepentingan umum, keamanan negara, perkembangan ekonomi nasional dan pelestarian fungsi lingkungan hidup. Upaya pengurangan hambatan perdagangan tersebut akan berjalan dengan baik apabila masing-masing negara memberlakukan standar wajib menerapkan Good Regulatory Practices dan melaksanakan notifikasi standarisasi ke WTO sesuai dengan ketentuan TBT Agreement.

Kata kunci: Standarisasi Produk, Technical Barrier to Trade Agreement, Good Regulatory Practices. 


\section{Pendahuluan}

Perdagangan internasional merupakan faktor yang sangat penting dalam meningkatkan kemajuan ekonomi negara-negara di dunia. Menurut sejumlah ahli. $^{2}$ jika perekonomian dunia ingin makmur dalam suasana yang berubah seperti sekarang perdagangan harus memainkan peranan vital. ${ }^{3}$

Richard Rosecrance memaparkan betapa besar kekuatan yang dapat diwujudkan suatu bangsa melalui kemampuan dagangnya. Kegiataan perdangangan mampu menggantikan ekspansi wilayah perang dan militer sebagai kunci pokok menuju kesejahteraan dan pencapaian kekuasaan internasional. Disimpulkannya bahwa manfaat perdagangan dan kerjasama internasional dewasa ini jauh melampaui manfaat persaingan militer dan perluasan wilayah. $^{4}$

Saat ini perhatian dunia usaha terhadap kegiatan bisnis internasional juga semakin meningkat, hal tersebut terlihat dari semakin berkembangnya arus peredaran barang, jasa, modal, dan tenaga kerja antar negara. Kegiatan bisnis dapat terjadi melalui hubungan ekspor impor, investasi, perdagangan jasa, lisensi, dan waralaba (lincense and franchise), hak atas kekayaan

${ }^{2}$ Trade Policies For A Better Future, Proposal For Action, GATT, Geneva, March 1995

3 Menurut salah satu taksiran para pakar GATT (lihat FOCUS, GATT Newsletter, October 1994) pendapatan global akan meningkat sebesar US \$ 500 Milyar pada tahun 2005 sebagai akibat pembukaan pasar pasca Putaran Uruguay, untuk suatu uraian yang lebih seksama tentang dampak dari manfaat GATT bagi negara-negara berkembang, (FOCUS, WTO Newsletter, No. 1, Januari-February 1995).

${ }^{4}$ Menurut Rosecrance Pilihan Pemerintah terhadap strategi perdagangan dalam hubungan internasional bukan hanya berasal dari manfaat perdagangan; pilihan itu mencerminkan kesulitankesulitan yang nampa dari kegagalan yang tak henti-hentinya dialami dalam sistem politik-militer. Sejak tahun 1945, beberapa negara haurs memikul beban pengeluaran yang sangat besar untuk keperluan kemiliteran, sementara itu negara lain cukup merasa beruntung karena menjadi negara cinta damai yang hanya mengandalkan perlindungan keamanan negara lain. Sementara Amerika Serikat menghabiskan 50\%a anggaran penelitian dan pengembangannya untuk keperluan persenjataan, jepang menghabiskan hampir 99\% untuk kegiatan produksi barang dagangan. Sementara itu laju pertumbuhan Uni Soviet menurun dari 6\% menjadi 4\% dan 2\% pertahun, dan investasi di sektor industri juga mengendor akibat tingginya anggaran pertahanannya, yaitu sebesar $12 \%$ hingga $14 \%$ terhadap GNP. Jepang, yang kurang dari 1\% Produk Nasional Bruto-nya dihabiskan untuk alat-alat perang. Mampu lebih meningkatkan kemajuan ekonominya melalui perdangangan dan peningkatan produktivitas. (Hata, Perdagangan Internasional Dalam Sistem GATT Dan WTO Aspek-Aspek Hukum Dan Non Hukum (Jakarta: Refika Aditama, 2006). Hlm. 1) 
intelektual atau kegiatan-kegiatan bisnis lainnya seperti perbankan, asuransi, perpajakan, dan sebagainya. ${ }^{5}$

Era Perdagangan internasional menggambarkan realitas perkonomian dunia dengan desain sistem yang terintegrasi dalam konfigurasi global, bahkan dapat mengarah secara signifikan untuk memperbaiki perekonomian suatu negara. Efek positif tersebut oleh Joseph Stiglitz dilontarkan sebagai bukti empiris yang pernah dilalui beberapa negara dalam menerapkan kebijakan perdagangan bebas:

"Trade liberalization created opportunities for economic development, but other factors determined the extent to which those opportunities were realized". 6

Ungkapan di atas menegaskan seberapa besarpun pembangunan ekonomi dapat diraih melalui perdagangan bebas tetap perlu memperhatikan faktor lain yang menentukan cakupan keberhasilannya. Inggris pernah sukses menerapkan keberhasian terobosan bidang teknologi untuk tampil sebagai negara industri, ekonomi dan industri jepang sukses melalui Restorasi Meiji diraih melalui kebijakan ketat sistem pendidikan, adaptasi teknologi barat dan stabilisasi institusional. $^{7}$

Perdagangan internasional dan kesejahteraan saling terkait satu dan lainnya. Perwujudan negara kesejahteraan (welfare state) merupakan salah satu tujuan kebijaksanaan ekonomi internasional termasuk pengendalian perdagangan melalui sistem proteksi. Kebijakan proteksi ditujukan bagi industri dalam negeri atau melindungi produksi dalam negeri dari persaingan barang impor. Kebijakan tersebut dijalankan dengan pengenaan tarif dan pembatasan kuota. Mekanisme proteksi diatur secara persuasif. Perlindungan tarif dibolehkan untuk menarik pemasukan, akan tetapi agar tidak menjadi hambatan dengan semena-mena manikkan tarif, kebijakan tersebut tidak boleh

\footnotetext{
5 Muhamaad Sood, Hukum Perdagangan Internasional (Jakarta: PT. Raja Grafindo Persada, 2011). Hlm.1

${ }^{6}$ Joseph E. Stiglitz and Andrew Charlton, Fair Trade For All How Trade Can Promote Development (New York: Oxford University Press inc, 2005). Hlm. 11

${ }^{7}$ Joseph E. Stiglitz and Andrew Charlton. Hlm. 12-13
} 
berlaku diskriminatif. ${ }^{8}$ Demikian halnya kebijakan pembatasan kuota ekspor dan impor masih diperbolehkan untuk melindungi neraca pembayaran luar negeri dan menjaga keseimbangan devisa. Setelah tujuan perlindungan itu tercapai, kebijakan restriksi kuantitatif harus dikurangi atau bahkan dihapus.

Upaya untuk mengurangi berbagai hambatan dan proteksi perdagangan antar negara mutlak diperlukan. Sebuah sistem dibentuk dalam serangkaian perjanjian pasca Perang Dunia II, seperti perjanjian multilateral General Agreement on Tariffs and Trade yang selanjutnya disingkat (GATT). Perjanjian tersebut semakin menguatakan komitmen sistem perdagangan internasional yang semakin lama semakin universal. Konsep internasionalisasi perdagangan merupakan tren global yang meninggalkan proteksi dagang nasional menuju perdagangan internasional yang berpola universal. ${ }^{9}$ Perundingan yang konsisten untuk mengurangi berbagai hambatan perdagangan dapat dicermati dalam salah satu isi perjanjian GATT, yaitu Agreement Technical Barrierss to Trade yang selanjutnya disingkat (TBT Agreement) yang memiliki peran sentral dalam menghapus hambatan teknis. ${ }^{10}$

Menurut Alan Deardorff dan Robert Stern membuat 5 kategori utama, yaitu quantitative restrictions, non tariff charges, government participation in trade, cumtoms procedures and administrative practice, and technical Barrierss to trade. Berdasarkan kategori ini, technical Barrierss to trade termasuk dalam ruang lingkup hambatan non tarif. ${ }^{11}$

TBT Agreement berperan penting mengurangi hambatan teknis perdagangan yang terkait dengan peraturan teknis (technical regulation), standar (standard), dan prosedur kesesuaian (conformity assesment

\footnotetext{
${ }^{8}$ Huala Adolf, Hukum Perdagangan Internasional (Jakarta: PT. Raja Grafindo Persada, 2013). Hlm. 19

9 Clive Schmitthoff menyatakan internasionalisasi GATT" ... The general trend of commercial law to move away from restrictions of national law to a universal and internasional conception..." didalam Ibid. hlm 26

${ }_{10}$ Nandang Sutrisno, "Efektifitas Ketentuan-Ketentuan World Trade Organization Tentang Perlakuan Khusus Dan Berbeda Bagi Negara Berkembang: Implementasi Dalam Praktek Dan Dalam Penyelesaian Sengekta," Jurnal Hukum Ius Quia Iustum 16, no. Edisi Khusus (2009). Hlm. 12

11 Nandang Sutrisno, Mewaspadai Dampak Perang Dagang China-Amerika, https://www.watyutink.com/opini/Mewaspadai-Dampak-Perang-Dagang-China-Amerika, Akses pada tanggal 24 Juli 2018
} 
procedure $).{ }^{12}$ Ketiga hal tersebut mengatur harmonisasi perdagangan bebas dengan menggunakan standar-standar internasional dalam mengatur simbol, pengepakan, penandaan atau pelabelan yang diterapkan untuk suatu produk menjamin kebijakan domestik yang tidak menghambat kemampuan eksportir mengakses pasar lokal. ${ }^{13}$

Indonesia sebagai negara anggota World Trade Organization yang selanjutnya disingkat (WTO) terikat untuk tunduk pada persetujuanpersetujuan multilateral terkait perdagangan internasional yang berada dibawah pengaturan WTO yang termasuk TBT Agreement. Sikap pemerintah Indonesia mengantisipasi hambatan teknis perdagangan internasional salah satunya adalah dengan mengeluarkan Undang-Undang Nomor 20 Tahun 2014 tentang Standardisasi Produk dan Penilaian Kesesuaian.

Program standardisasi perlu dikendalikan agar tidak menimbulkan proteksi yang menghambat. Standardisasi yang cenderung protektif dapat diterapkan untuk melindungi kepentingan nasional, namun menghambat ekspor Negara-Negara mitra dagang ke Indonesia. Begitu pula sebaliknya, jika program standardisasi cenderung diterapkan, aliran barang dan jasa impor akan mengancam kepentingan umum, menekan produksi dan komoditas dalam negeri serta posisi tukar mata uang. ${ }^{14}$ Perihal ini lah yang menjadi dasar untuk melakukan kajian bagaimana pengaturan standardisasi produk yang dewasa ini dilakukan oleh Indonesia jika di tinjau dari TBT Agreement dalam bentuk jurnal ilmiah ini.

Penelitian yang membahas tentang pengaturan standardisasi menurut TBT Agreement sudah cukup banyak dilakukan oleh para peneliti terdahulu. Berdasarkan hasil penelusuran terhadap beberapa literatur yang telah

${ }^{12}$ Preamblume TBT Agreement disebutkan"... To Ensure that technical regulations and standarts, including packaging, marking and labelling requirment, and procedures for assesment of conformity with technical regulations and standarts do not create unnecessary obstacles to international trade."

13 Syukri Hidayatullah, "Perbandingan Hukum Pengaturan Standardisasi Menurut Agreement TBT Dan Undang-Undang No.7 Tahun 2014 Tentang Perdagangan," Arena Hukum 9, no. 2 (2016). Hlm. 273

${ }^{14}$ Syukri Hidayatullah. Hlm. 274 
dilakukan, maka setidaknya ditemukan beberapa literatur yang membahas mengenai permasalahan ini.

Pertama, Syukri Hidayatullah dengan judul Perbandingan Hukum Pengaturan Standardisasi Menurut Agreement TBT dan Undang-Undang Nomor 7 tahun 2014 tentang Perdagangan pada tahun 2016 yang dalam penelitiannya tersebut membahas tentang analisis ekonomi terhadap hukum dalam Agreement on Technical Barrier to Trade dibandingkan dengan standardisasi yang diatur dalam Undang-Undang Nomor 7 Tahun 2014 tentang Perdagangan serta efektivitas standardisasi sebagai instrumen hukum untuk mengurangi hambatan teknis perdagangan bebas. Hasil penelitian tersebut menunjukkan bahwa analisis ekonomi mengasumsikan perilaku rasional Negara untuk mencapai kemakmuran yang sebesar-besarnya melalui perjanjian dagang multilateral. Perjanjian multilateral merupakan pilihan sikap yang efisien karena menghasilkan perjanjian yang universal. Dengan demikian, alokasi norma standardisasi dalam Undang-Undang Nomor 7 Tahun 2014 tentang Perdagangan sinkron dengan Agreement on Technical Barrier to Trade. Standardisasi bekerja sebagai instrumen hukum dalam pasar bebas melalui perlindungan lingkungan, keselamatan konsumen, kemanan dan kesehatan publik. Instrumen standardisasi membantu konsumen membandingkan karakteristik produksi dan menambah preferensi bagi konsumen untuk produk sejenis. ${ }^{15}$

Kedua, Darminto Hartono Paulus, Fx. Joko Priyono dan Karina Imasepti dengan judul Implementasi Technical Barriers to Trade Agreement dalam Kasus Pemberian Label "Warning” Pada Produk PT. Sido Muncul pada tahun 2016 yang dalam penelitiannya tersebut membahas tentang Implementasi Technical Barriers to Trade Agreement dalam Kasus Pelabelan "Warning" pada produk PT. Sido Muncul mengingat sebenarnya dalam perdagangan Internasional hambatan teknis merupakan hal yang dilarang karena dapat menimbulkan persaingan yang tidak fair, namun terdapat beberapa pengecualian dalam General Agreement on Tariff and Trade (GATT)

\footnotetext{
${ }^{15}$ Syukri Hidayatullah. Hlm. 271
} 
dan secara lebih khusus diatur dalam Technical Barriers to Trade Agreement. Hambatan teknis yang dimaksud dalam kasus ini adalah Peraturan Teknis dan diatur dalam Pasal II TBT Agreement. ${ }^{16}$

Mencermati dua penelitian terdahulu di atas, maka dapat dikatakan penelitian ini berbeda dengan penelitian tersebut, adapun unsur kebaruan dalam penelitian ini terletak pada kajian isu hukum masing-masing penelitian, yang dalam kajian ini membahas tentang pengaturan dan penerapan standardisasi produk di Indonesia di tinjau dari ketentuan TBT Agreement serta tentang perumusan Standar Nasional Indonesia dan penetapan standar nasional secara wajib.

\section{Rumusan Masalah}

Berdasarkan permasalahan yang telah dijelaskan di atas, maka batasan masalah dalam penelitian ini, yaitu bagaimana pengaturan dan penerapan standardisasi produk di Indonesia di tinjau dari ketentuan Technical Barriers to Trade (TBT) Agreement serta bagaimana perumusan Standar Nasional Indonesia dan penetapan standar nasional secara wajib.

\section{Tujuan Penelitian}

Tujuan penelitian ini adalah untuk mengkaji secara mendalam pengaturan dan penerapan standardisasi produk di Indonesia di tinjau dari ketentuan Technical Barriers to Trade (TBT) Agreement serta menganalisa perumusan Standar Nasional Indonesia dan penetapan standar nasional secara wajib.

\section{Metode Penelitian}

Penelitian ini merupakan penelitian hukum normatif dengan menggunakan studi kepustakaan yaitu penelitian hukum yang meletakkan

\footnotetext{
${ }^{16}$ Karina Imasepti, Darminto Hartono Paulus, Fx. Joko Priyono, "Implementasi Technical Barriers to Trade Agreement dalam Kasus Pemberian Label 'Warning' Pada Produk PT. Sido Muncul," Diponegoro Law Review 5, no. 2 (2016). Hlm. 3
} 
hukum sebagai sebuah bangunan sistem norma. ${ }^{17}$ Penelitian hukum normatif ini digunakan dalam memahami pengaturan standardisasi produk di Indonesia di tinjau dari ketentuan TBT Agreement. Pendakatan penelitian ini adalah pendekatan Perundang-undangan (statue approach). Pendekatan perundangundangan dilakukan dengan mengkaji berbagai peraturan Perundangundangan atau yurisprudensi terkait isu hukun yang diteliti.

Bahan hukum yang akan digunakan dalam penelitian ini adalah (1). Bahan hukum primer, yaitu bahan-bahan hukum pokok yang mengikat atau memiliki otoritas. Dalam penulisan ini, digunakan bahan hukum primer berupa General Agreement on Tariffs and Trade (GATT), Technical Barriers To Trade Agreeement (TBT Agreement), Sanitary Phytosanitary Measures Agreement (SPS Agreement), Titie 27 California Code Regulation, Pasal 25306 , UndangUndang Nomor 20 Tahun 2014 tentang Standardisasi Produk dan Penilaian Kesesuaian, Peraturan Pemerintah Republik Indonesia Nomor 55 Tahun 2012 tentang Kendaraan, Peraturan Menteri Pertanian Nomor 58 Tahun 2007 tentang Pelaksanaan Sistem Standardisasi Nasional di Bidang Pertanian, serta Peraturan Kepala Badan Standarisasi Nasional Nomor 301 Tahun 2011 tentang Pedoman Pemberlakuan SNI secara wajib. (2). Bahan hukum sekunder, yaitu bahan-bahan hukum yang mendukung dan memperjelas bahan hukum primer yang berupa dokumen-dokumen resmi, meliputi karya tulis, buku-buku teks, jurnal-jurnal hukum dan komentar-komentar atas putusan pengadilan. (3). Bahan non-hukum, yaitu bahan yang memberikan penjelasan maupun petunjuk terhadap bahan hukum primer maupun sekunder yang telah ada seperti Kamus Besar Bahasa Indonesia dan lain sebagainya yang digunakan untuk mencari istilah-istilah dalam rangka menjelaskan hal-hal yang digunakan dalam bahan hukum primer maupun bahan hukum sekunder.

Teknik Pengumpulan data yang akan digunakan dalam penelitian hukum ini adalah studi kepustakaan yang terbatas pada penggunaan dokumen dan

17 Mukti Fajar ND dan Yulianto Achmad, Dualisme Penelitian Hukum Normatif \& Empiris (Yogyakarta: Pustaka Pelajar, 2010). Hlm. 34 
bahan pustaka. Pengumpulan data dilakukan dengan cara mengumpulkan datadata tertulis yang berkaitan dengan masalah yang diteliti.

Analisa bahan hukum dalam penilitian ini menggunakan penalaran deduktif, yaitu menganalisa beberapa premis hukum dalam kajian ini untuk ditarik pada sebuah satu kesimpulan yang dapat menggambarkan jawaban dari rumusan masalah di atas.

\section{Hasil Penelitian dan Pembahasan}

\subsection{Tinjauan Yuridis Standardisasi Produk dalam Technical Barriers To}

\section{Trade (TBT) Agreement}

Dalam praktik hukum dagang internasional, WTO sebagai organisasi perdagangan dunia memberikan keleluasaan bagi Negara anggota membentuk peraturan nasionalnya sendiri, namun harus mengacu pada ketentuan Internasional yang ada. Menurut Mitsuo Matsushita, Thomas J. Schoenbaum dan Petros C Mavroidis dalam buku The World Trade Organization Law, Practice, and Policy bahwa Standardisasi domestik memainkan peran yang serupa dengan peraturan teknis. ${ }^{18}$ Selanjutnya Article 4.1 TBT memperjelas bahwa semua anggota WTO terikat oleh aturan yang ditetapkan dalam Code of Good Practice sebagaimana di atur didalam Annex 3 TBT Agreement. ${ }^{19}$ Article 4.2 TBT menjelaskan bahwa standardisasi yang telah mematuhi code of good practice harus diakui oleh anggota sesuai dengan prinsip-prinsip dalam perjanjian ini. ${ }^{20}$

${ }^{18}$ Thomas J. Schoenbaum \& Petros C. Mavroidis Mitsuo Matsushita, The World Trade Organization Law, Practice and Policy (United States: Oxford University Press inc, 2006). Hlm. 499

${ }^{19}$ Article 4.1 TBT makes it clear that all WTO members are bound by the displines laid down in the Code of Good Practice Which is found out in Annex 3 of the TBT Agreement. Compliance with the Code of Good Pracitice amounts ipso facto to compliance with the principles of the TBT Agreement.

${ }^{20}$ Art 4.2 TBT is Patient Standardizing bodies that have accepted and are complying with the Code of Good Practice Shall be acknowledge by the Members as complying with the principles of this Agreement. 
Untuk menghindari tumpang tindih aturan yang bertolak belakang belakang antara satu negara dengan negara lainnya, maka ditetapkan sebuah aturan yang menjadi prinsip-prinsip perdoman dalam penerapan aturan teknis standardisasi yang terdapat dalam Article II Technical Regulations and Standars, TBT Agreement yang diuraikan sebagai berikut:

With respect to their central government bodies:

1.1. Members shall ensure that in respect of technical regulations, product imported from the territory of any Member shall be accorded treatment no less favourable that accorded to like products of national origin and to like products originating in any other country...

Articel 2.1 di atas menjelaskan bahwa makna prinsip nondiskriminasi tersebut adalah dimana ketentuan ini mengharuskan untuk tidak membeda-bedakan dalam penerapan kebijakan antara negara satu dengan negara lainnya, artinya tidak boleh memberikan kemudahan hanya pada satu negara saja tanpa perlakuan yang sama dengan anggota lainnya. $^{21}$

1.2. Members shall ensure that technical regulations are not prepared, adopted or applied with a view to or with the effect of creating unnecessary obstacles to international trade. For this purpose, technical regulations shall not be more traderestrictive than necessary to fulfil a legitimate objective, taking account of the risks non-fulfilment would create. Such legitimate objectives are, inter alia: national security requirements; the prevention of deceptive practices; protection of human health or safety, animal or plant life or health, or the environment. In assessing such risks, relevant elements of consideration are, inter alia: available scientific and technical information, related processing technology or intended enduses of products.

2.5. A Member preparing, adopting or applying a technical regulation which may have a significant effect on trade of other Members shall, upon the request of another Member, explain the justification for that technical regulation in terms

${ }^{21}$ Joko Priyono Karina Imasepti, Darminto Hartono Paulus, "Implementasi Technical Barrierss To Trade Agreement Dalam Kasus Pemberian Label 'Warning' Pada Produk PT. Sido Muncul," Diponegoro Law Review 5, no. 2 (2016). Hlm. 6 
of the provisions of paragraphs 2 to 4 . Whenever a technical regulation is prepared, adopted or applied for one of the legitimate objectives explicitly mentioned in paragraph 2, and is in accordance with relevant international standards, it shall be rebuttably presumed not to create an unnecessary obstacle to international trade.

Selanjutnya Article 2.2 dan 2.5 TBT Agreement dimaknai bahwa peraturan teknis disusun, ditetapkan dan diterapkan tidak dengan maksud untuk atau tidak dengan dampak menimbulkan hambatan yang tidak perlu dalam perdagangan Internasional serta mewajibkan suatu negara pembuat kebijakan untuk memberikan penjelasan secara rinci alasan dibuatnya kebijakan tersebut.

2.3. Technical regulations shall not be maintained if the circumstances or objectives giving rise to their adoption no longer exist or if the changed circumstances or objectives can be addressed in a less trade-restrictive manner.

Article 2.3 TBT Agreement dimaknai bahwa suatu Peraturan Teknis tidak boleh dipertahankan apabila keadaan atau tujuan yang menyebabkan diterapkannya peraturan tersebut tidak ada lagi, atau apabila keadaan dan tujuan yang berubah tersebut dapat dicapai dengan cara kurang membatasi perdagangan.

2.4. Where technical regulations are required and relevant international standards exist or their completion is imminent, Members shall use them, or the relevant parts of them, as a basis for their technical regulations except when such international standards or relevant parts would be an ineffective or inappropriate means for the fulfilment of the legitimate objectives pursued, for instance because of fundamental climatic or geographical factors or fundamental technological problems.

2.6. With a view to harmonizing technical regulations on as wide a basis as possible, Members shall play a full part, within the limits of their resources, in the preparation by appropriate international standardizing bodies of international standards for products for which they either have adopted, or expect to adopt, technical regulations. 
Article 2.4 dan 2.6 TBT Agreement menyatakan bahwa negara anggota harus menggunakan standar internasional yang relevan sebagai dasar untuk Peraturan Teknis mereka, dengan begitu maka akan terbentuk harmonisasi antara peraturan satu dengan yang lainnya. Hal ini memudahkan penyesuaian aturan yang memakan waktu lama. ${ }^{22}$

2.9 Whenever a relevant international standard does not exist or the technical content of a proposed technical regulation is not in accordance with the technical content of relevant international standards, and if the technical regulation may have a significant effect on trade of other Members, Members shall:

2.9.1 publish a notice in a publication at an early appropriate stage, in such a manner as to enable interested parties in other Members to become acquainted with it, that they propose to introduce a particular technical regulation;

2.9.2 notify other Members through the Secretariat of the products to be covered by the proposed technical regulation, together with a brief indication of its objective and rationale. Such notifications shall take place at an early appropriate stage, when amendments can still be introduced and comments taken into account;

2.9.3 upon request, provide to other Members particulars or copies of the proposed technical regulation and, whenever possible, identify the parts which in substance deviate from relevant international standards;

2.9.4 without discrimination, allow reasonable time for other Members to make comments in writing, discuss these comments upon request, and take these written comments and the results of these discussions into account.

Article 2.9 TBT Agreement berisi mengenai prinsip transparansi yang mengharuskan setiap negara anggota ketika membuat atau menerapkan suatu peraturan teknis, diumumkan dan memberikan kesempatan kepada publik untuk memberikan tanggapan mengenai peraturan teknis tersebut. sebagai contoh pada kasus pemberian label "Warning" pada produk PT. Sido Muncul di California. Sebelum dijadikan sebagai daftar bahan kimia yang wajib diberi label maka paling

\footnotetext{
${ }^{22}$ Karina Imasepti, Darminto Hartono Paulus. Hlm.
} 
tidak 60 hari sebelumnya harus sudah ada identifikasi oleh badan otoritas baru setelahnya dinotifikasi pada California Regulatory Notice. Salinan terhadap pemberitahuan tersebut diberikan pada komite identifikasi karsinogen atau komite identifikasi Dart dan kurang dari 30 hari komite tersebut harus meninjau dan mengomentari usulan akan daftar yang diusulkan. Kemudian tiga puluh hari setelah penerbitan pemberitahuan, pihak-pihak yang berkepentingan dipersilahkan mengajukan keberatan maupun memberi komentar disertai dokumen pendukung. ${ }^{23}$

Pada dasarnya TBT Agreement merupakan suatu kesatuan dengan The Agreement on Sanitary and Phytosanitary Measures (SPS agreement) yang bersifat saling melengkapi yang disahkan melalui Putaran Uruguay dan sebagai elaborasi dari Standards Code Hasil putaran Tokyo 1979. Jika SPS Agreement di rancang mengatur perlindungan bagi kehidupan ekologi dan lingkungan, maka TBT Agreement mengakomodir ketentuan standar teknis yang tidak diatur dalam SPS Agreement. ${ }^{24}$

Ketentuan TBT Agreement bekerja melalui tiga konsep yang tidak termuat dalam SPS Agreement, yaitu regulasi teknis, standar dan prosedur penilaian kesesuaian dan berlaku untuk semua produk. ${ }^{25}$ Definisi ketiga konsep ini dapat ditemui dalam Annex 1 TBT Agreement. Secara sistematis kaidah-kaidah TBT Agreement seperti regulasi teknis, standar dan penilaian kesesuaian dapat kontruksikan sebagai berikut $:^{26}$

${ }^{23}$ Article 25306 Titie 27 California Code Regulation

${ }^{24}$ The Uruguay Round elaborated the Tokyo Round Standards Code into two new agreements governing standards. The Agreement on Sanitary and Phytosanitary Measures (SPS Agreement) Addresses measures designed to protect human, animal and plant life, and health. The Technical Barrierss to Trade Agreement covers other technical standards and measures not covered by the SPS Agreement. Under the "Umbrella" Provisions of the WTO, all Parties to the GATT are obligated to adhere to both of these Agreements" (Michael J. Trebilcock and Robert Howse, The Regulations of Internasional Trade Second Edition (London: Routledge, 1999). Hlm. 132)

25 “Agreement TBT Applies to all product, including industrial and agricultural products, but does not include SPS Measures. It covers technical regulations, standars and conformity assesment procedures, as defined in Annex 1 of the Agreement.".

26 Syukri Hidayatullah, "Perbandingan Hukum Pengaturan Standardisasi Menurut Agreement TBT Dan Undang-Undang No.7 Tahun 2014 Tentang Perdagangan.” Hlm. 279 
Tabel 1. Pembagian kaidah TBT Agreement

\begin{tabular}{|l|l|l|l|}
\hline Kaidah & Bentuk & Sifat & Tata Cara \\
\hline Regulasi Teknis & $\begin{array}{l}\text { Dokumen Wajib } \\
\text { (Mandatory) }\end{array}$ & $\begin{array}{l}\text { Menetapkan } \\
\text { karakteristik } \\
\text { produk, proses dan } \\
\text { metode produksi }\end{array}$ & $\begin{array}{l}\text { Persyaratan } \\
\text { terminologi, } \\
\text { simbol, } \\
\text { pengemasan, } \\
\text { penandaan atau } \\
\text { pelabelan }\end{array}$ \\
\hline Standar & $\begin{array}{l}\text { Dokumen Tidak } \\
\text { Wajib (Voluntary) }\end{array}$ & $\begin{array}{l}\text { Menjadi wajib bila } \\
\text { ditetapkan oleh } \\
\text { badan yang } \\
\text { berwenang } \\
\text { berdasar konsesus } \\
\text { internasional. }\end{array}$ & $\begin{array}{l}\text { Persyaratan } \\
\text { terminologi, } \\
\text { simbol, } \\
\text { pengemasan, } \\
\text { penandaan atau } \\
\text { pelabelan, } \\
\text { pedoman atau } \\
\text { tata cara }\end{array}$ \\
\hline $\begin{array}{l}\text { Penilaian } \\
\text { Kesesuaian }\end{array}$ & $\begin{array}{l}\text { Prosedur yang } \\
\text { digunakan secara } \\
\text { langsung atau } \\
\text { secara tidak } \\
\text { langsung }\end{array}$ & $\begin{array}{l}\text { Menentukan } \\
\text { regulasi teknis dan } \\
\text { standar yang } \\
\text { memenuhi } \\
\text { persyaratan atau } \\
\text { tidak memenuhi } \\
\text { persyaratan. }\end{array}$ & $\begin{array}{l}\text { Uji coba, inpeksi, } \\
\text { evaluasi, } \\
\text { verifikasi, } \\
\text { registrasi, } \\
\text { akreditasi atau } \\
\text { kombinasinya. }\end{array}$ \\
& & & \\
\hline
\end{tabular}

Sumber : Tebel dibuat berdasarkan konstruksi penulis

Aplikasi regulasi teknis tersusun dari tiga hal pokok, yaitu identiikasi, karakteristik produk dan kewajiban penerapan. Sebuah produk diindentifikasi dengan memuat dokumen karakteristik yang bersifat wajib. Dokumen tersebut wajib mencantumkan terminologi, simbol, pengemasan dan pelabelan yang menggambarkan dengan tepat komposisi sebuah produk dari bidang-bidang tertentu yang telah diidentifikasi sebelumnya, seperti produk perkebunan, argikultur, holtikultural, industri manufaktor, elektronik mekanikal dan sebagainya. Bentuk regulasi teknis merupakan potensi terbesar untuk membatasi perdagangan internasional. Menurut Arthur Appleton, karakteristik 
produk yang tidak memenuhi persyaratan aplikasi regulasi teknis akan dilarang dijual.

Perumusan standar pada dasarnya serupa dengan regulasi teknis kecuali sifat berlakunya yang sukarela. Norma sukarela ini dipertimbangkan karena beberapa institusi mengeluarkan banyak peraturan dalam membentuk standar yang tidak mengikuti bagi pelaku pasar. Sebagai contoh sebuah produk elektronik membutuhkan Standardisasi voltase, atau sebuah perusahaan manufaktur membutuhkan ukuran baut dan mur yang terStandardisasi sehingga produk tersebut dapat mudah diperbaiki dan dibongkkar pasang dimana saja tanpa harus belaku wajib menggunakan salah satu produk saja selama produk tersebut memenuhi karakteristik voltase atau ukuran baut. Penerapan yang berbeda ini diartikan bahwa sekalipun TBT Agreement membedakan perlakukan sifat wajib dan sukarela, kekuatan mengikatnya kembali ditentukan oleh status formal. Formalitas tersebut ditentukan oleh yuridiksi domestik.

Conformity assesment procedures atau prosedur penilaian kesesuaian merupakan kaidah ketiga dari mekanisme hambatan teknis perdagangan. Penilaian tersebut pada umumnya dilakukan dengan tiga cara:

5.1.1. Penilaian satu pihak, dilakukan dengan cara deklarasi pemasok secara uniteral. Kesesuaian tersebut berdasarkan penilaian dan pengendalian mandari (self assesment and self-control).

5.1.2. Penilaian pihak kedua, dilakukan oleh pembeli atau pengimpor atau oleh lembaga inpeksi/pengujian.

5.1.3. Penilaian pihak ketiga, dilakukan secara independen oleh sebuah lembaga baik yang ditunjuk pemasok atau pembeli. $^{27}$

27 Michaels Koebele \& Max Planck, Commentaries on World Trade Law Volume (Leaden: Koninklijke Brill NV, 2007). Hlm. 187 
Tahapan penilaian berikutnya adalah pengakutan formal. Hasil penilaian kesesuaian termuat dalam tanda sertifikasi yang tertera pada produk atau kemasannya. Selain sertifikasi, proses penilaian sebuah produksi dapat pula mendapatkan pengakuannya dengan diterbitkannya akreditasi. Akreditasi menjadi penting ketika tidak ada otoritas resmi yang berada dalam posisi untuk menilai kualitas dan pengetahuan atas suatu regulasi teknis atau standar tertentu.

\subsection{Pengaturan dan Penerapan Standardisasi Produk di Indonesia di} Tinjau dari Ketentuan Technical Barriers to Trade (TBT) Agreement

Regulasi standardisasi nasional telah mengalami pergeseran paradigma, dari yang semula dimanfaatkan untuk menciptakan harmonisasi industri berkembang menjadi sarana yang strategis dalam perdagangan. ${ }^{28}$

Telah diketahui bersama bahwa setiap kebijakan standardisasi yang WTO haruslah diketahui dan disetujui oleh negara-negara anggota WTO yang khususnya oleh negara yang berpartisipasi langsung dalam perdagangan tersebut. $^{29}$ Indonesia memiliki badan resmi yang bertanggung jawab sebagai terbitan, pengumumman dan layanan informasi atau National Enquiry Points yang selanjutnya disebut dengan (NEPS) yang berkaitan dengan perjanjian TBT Agreement, yakni Badan Standardisasi Nasional yang selanjutnya disebut dengan (BSN). BSN sebagai lembaga resmi di Indonesia yang bertanggung jawab untuk membuat kebijakan standardisasi nasional sebagai konsekuensi dari pemberlakukan TBT Agreement dan telah memiliki standar yang di kenal dengan nama Standar Nasional Indonesia yang selanjutnya disebut

28 Syukri Hidayatullah, "Perbandingan Hukum Pengaturan Standardisasi Menurut Agreement TBT Dan Undang-Undang No.7 Tahun 2014 Tentang Perdagangan.” Hlm. 279

${ }^{29}$ Standardisasi adalah proses merencanakan, merumuskan, menetapkan, menerapkan, memberlakukan, memelihara, dan mengawasi standar yang dilaksanakan secara tertib dan berkerja sama dengan semua Pemangku Kepentingan. (Pasal 1 Angka 1 Undang-Undang No.20 Tahun 2014 tentang Standarisasi Produk dan Penilaian Kesesuaian). 
dengan (SNI). ${ }^{30}$ SNI yang hendak diciptakan haruslah memenuhi sejumlah norma yang berlaku dalam dunia perdagangan internasional. Keterbukaan, tranparansi, ketidakberpihakan, keefektifan, koheren dan berdimensi pembangunan merupakan norma atau prinsip dalam perdagangan bebas.

Perumusan SNI dilaksanakan oleh BSN, dalam melaksanakan perumusan SNI, BSN membetuk Komite Teknis, komite teknis terdiri dari unsur:

5.2.1. Pemerintah dan/atau Pemerintah Daerah.

5.2.2. Pelaku Usaha dan/atau asosiasi terkait.

5.2.3. Konsumen dan/atau asosiasi terkait.

5.2.4. Pakar dan/atau akademisi.

Kemudian melalui perumusan SNI membuat rancangan SNI yang ditetapkan menjadi SNI dengan keputusan kepala BSN. Berkaitan dengan penerapan SNI dilakukan dengan cara menerapkan persyaratan SNI terhadap barang, jasa, sistem, proses atau personal. Penerapan SNI dilaksanakan secara sukarela atau diberlakukan secara wajib. Penerapan SNI dibuktikan melalui pemilikan sertifikat dan/atau pembubuhan Tanda SNI dan/atau Tanda kesesuaian.

\subsubsection{Penerapan SNI Secara Sukarela}

SNI dapat diterapkan secara sukarela oleh Pelaku Usaha, Kementrian dan/atau lembaga pemerintah nonkementrian, dan/atau Pemerintah Daerah. Pelaku Usaha, Kementrian dan/atau non Kementrian, dan/atau Pemerintah Daerah yang telah mampu menerapkan SNI dapat mengajukan Sertifikasi kepada Lembaga Penilaian Kesesuaian yang selanjutnya disebut dengan (LPK) yang telah diakreditasi oleh Komite Akreditasi Nasional yang selanjutnya disebut dengan (KAN). Selanjutnya LPK yang telah

30 Standar Nasional Indonesia yang selanjutnya disingkat SNI adalah Standar yang ditetapkan oleh BSN dan berlaku diwilayah Negara Kesatuan Republik Indonesia.(Pasal 1 angka 7 Undang-Undang No.20 Tahun 2014 tentang Standarisasi Produk dan Penilaian Kesesuaian). 
diakreditasi oleh KAN memberikan Sertifikat kepada pemohon sertifikat.

Pemenuhan terhadap persyaratan SNI dibuktikan melalui kegiatan Penilaian kesesuaian. Kegiatan penilaian kesesuian dilakukan melalui pengujian, inspeksi dan/atau Sertifikasi. Dalam hal SNI belum ditetapkan atau untuk kepentingan nasional, pengujian, inspeksi dan/atau Sertifikasi dapat menggunakan standar lain. Dalam hal terdapat perjanjian saling pengakutan antara KAN dan lembaga Akreditasi Internasional, kegiatan Penilaian Kesesuaian dapat dilakukan oleh LPK diluar negeri yang telah diakreditasi di negara tersebut berdasarkan asas timbal balik. Selanjutnya dalam hal Indonesia menjadi anggota organisasi internasional, kegiatan Penilaian Kesesuaian dapat dilakukan oleh LPK yang diakui oleh organisasi tersebut.

\subsubsection{Penerapan SNI Secara Wajib}

Pada dasarnya penerapan SNI bersifat sukarela untuk menjamin keberterimaan dan pemanfaat SNI secara luas, penerapan norma keterbukaan bagi semua pemangku kepentingan, transparan dan tidak memihak, serta selaras dengan perkembangan standar internasional merupakan faktor yang sangat penting. Namun untuk keperluan melindungi kepentingan umum, keamanan negara, perkembangan ekonomi nasional dan pelestarian fungsi lingkungan hidup, pemerintah dapat saja memberlakukan SNI tertentu secara wajib.

Pemberlakukan SNI wajib dilakukan melalui penerbitan regulasi teknis oleh instansi pemerintah yang memiliki kewenangan untuk meregulasi kegiatan dan peredaran produk (regulator). Dalam hal ini, kegiatan produk yang tidak memenuhi ketentuan SNI menjadi terlarang.

Cara yang paling baik adalah membatasi penerapan SNI wajib bagi kegiatan atau produk yang memiliki tingkat resiko yang 
cukup tinggi, sehingga pengaturan kegiatan dan peredaran produk mutlak diperlukan.

Pemberlakuan SNI wajib perlu didukung oleh pengawasan pasar, baik pengawasan pra-pasar untuk menetapkan kegiatan atau produk yang telah memenuhi ketentuan SNI wajib tersebut maupun pengawasan pasca-pasar untuk mengawasi dan mengkoreksi kegiatan atau produk yang belum memenuhi ketentuan SNI itu. Apabila fungsi penilaian kesesuai terhadap SNI yang bersifat sukarela merupakan pengakutan, maka bagi SNI yang bersifat wajib penilaian kesesuaian merupakan salah satu persyaratan yang harus dipenuhi oleh semua pihak yang terkait. Dengan demikian penilaian kesesuaian berfungsi sebagai bagian dari pengawasan pra-pasar yang dilakukan oleh regulator.

Mengingat bahwa pemberlakuan regulasi teknis disuatu negara juga berlaku untuk produk impor, maka untuk menghindarkan terjadi hambatan perdagangan internasional/negara anggota WTO termasuk indonesia telah menyepakati TBT Agreement. Upaya pengurangan hambatan perdagangan tersebut akan berjalan dengan baik apabila masing-masing negara memberlakukan standar wajib menerapkan Good Regulatory Practices. $^{31}$

\subsection{Perumusan Standar Nasional Indonesia dan Penetapan Standar Nasional Secara Wajib}

Untuk menyesuaikan dengan perkembangan penerapan standar serta pemberlakukan regulasi teknis berbasis standar di tingkat nasional, regional, dan internasional, dibutuhkan pedoman yang dapat dijadikan sebagai acuan. Oleh karena itu BSN menerbitkan Peraturan

31 http://www.bsn.go.id/main/bsn/isi_bsn/20166/penerapan-sni, Akses pada tanggal 21 Juli 2018 
Kepala Badan Standardisasi Nasional Nomor 301 Tahun 2011 tentang Pedoman Pemberlakuan SNI secara wajib.

Pedoman Standarisasi Nasional yang selanjutnya disebut dengan (PSN) ini merupakan pedoman bagi Instansi teknis dalam memberlakukan suatu regulasi teknis secara wajib yang berbasis SNI yang terkait dengan TBT Agreement, mencakup persiapan dan kajian pemberlakuan SNI secara wajib, program nasional regulasi teknis, perumusan regulasi teknis, notifikasi, penetapan, implementasi, pengawasan, evaluasi, dan kaji ulang regulasi teknis. ${ }^{32}$

Meskipun penetapan regulasi teknis merupakan wewenang penuh instansi teknis, tetapi dalam proses perumusannya instansi teknis mengikutsertakan para pemangku kepentingan seperti pemerintah, pelaku usaha, konsumen, Lembaga Penilaian Kesesuaian (LPK), BSN dan KAN guna mendapatkan masukan yang diperlukan. Pelaksanaan dengan pendapat publik (Public Hearing) dapat dilakukan untuk mendapatkan umpan balik dari pihak-pihak yang berkepentingan sehingga pemahaman dan penerapan regulasi teknis lebih bermanfaat.

Selanjutnya suatu rancangan regulasi teknis harus dinotifikasikan ke WTO sesuai dengan ketentuan dalam perjanjian TBT-WTO, notifikasi dilakukan melalui BSN sebagai Notification body dan enquiry point, notifikasi harus dilaksanakan paling singkat enam puluh (60) hari sebelum regulasi teknis ditetapkan untuk memberikan

\footnotetext{
${ }^{32}$ Instansi Teknis adalah kementrian atau Lembaga Pemerintah Non Kementrian (LPNK) yang salah satu kegiatannya melakukan kegiatan standardisasi. Sedangkan istilah Regulasi teknis dapat ditemukan didalam Lampiran 1 Peraturan Kepala Badan Standarisasi Nasional Nomor 301 Tahun 2011 tentang Pedoman Pemberlakuan SNI secara wajib yang menyatakan: regulasi teknis adalah dokumen yang menetapkan karakteristik barang dan/atau jasa atau metode dan proses yang terkait dengan barang dan/atau jasa tersebut, termasuk persyaratan administratif yang sesuai yang pemenuhannya bersifat wajib. Regulasi teknis dapat juga secara khusus mencakup terminologi, simbol, persyaratan pengemasan, penandaan atau pelabelan yang digunakan pada barang dan/atau jasa, proses atau metode produksi. Hal tersebut juga terdapat di dalam Annex 1 TBT Agreement yang menyatakan Technical Regulations is a document which lays down product characteristics or their related processes and production methods, including the applicable administrative provisions, with which compliance is mandatory. It may also include or deal exclusively with terminology, packaging, marking or labeling requirements as the apply to a product, process or production method.
} 
kesempatan kepada pihak berkepentingan didalam dan luar negeri untuk memberikan masukan dan tanggapan sesuai dengan ketentuan TBT-WTO, dalam hal regulasti teknis berkaitan dengan keamanan, keselamatan, kesehatan, serta pelestarian fungsi lingkungan hidup atau keamanan negara harus segera diatasi, ketentuan tersebut dapat diabaikan dengan catatan bahwa regulasi teknis tersebut harus segera dinotifikasi ke WTO, paling lama 1 (satu) bulan setelah ditetapkan. Selanjutnya berkaitan dengan tanggapan BSN melaporkan hasil notifikasi berserta masukan dan tanggapan dari negara-negara lain kepada instansi teknis yang terkait untuk dijadikan pertimbangan. ${ }^{33}$

Berkaitan dengan implementasi regulasi teknis, setelah penetapan regulasi teknis, pelaku usaha harus melakukan langkahlangkah yang penyesuaian barang dan/atau jasa dan kegiatan produksi untuk memenuhi persyaratan dalam regulasi teknis atau melakukan penarikan barang dan/atau jasa yang telah beredar di pasar yang tidak sesuai dengan persyaratan dalam regulasti teknis, selain itu regulasi teknis harus menetapkan waktu transisi yang cukup untuk menyesuaikan persyaratan tersebut dengan mempertimbangkan sifat barang dan/atau jasa, kesiapan LPK, dan kemampuan pelaku usaha. Dalam implementasi regulasi teknis, pemangku kepentingan dapat menyampaikan pengaduan kepada instansi teknis yang menyangkut isi regulasi teknis, seperti pertimbangan kebijakan yang diambil, standar

${ }^{33}$ Butir 6 Lampiran 1 Peraturan Kepala Badan Standarisasi Nasional Nomor 301 Tahun 2011 tentang Pedoman Pemberlakuan SNI secara wajib dan 2.10 Article TBT Agreement yang menyatakan Subject to the provisions in the lead-in to paragraph 9, where urgent problems of safety, health, enviromental protection or national security arise or threaten to arise for a Member, that Member may omit such of the steps enumerated in paragraph 9 as it finds necessary, provided that the Member, upon adoption of a technical regulation, shall:

1. notify immediately other Members Through the Secretariat of the particular technical regulation and the products covered, with a brief indication of the objective and the rationale of the technical regulation, including the nature of the urgent problems;

2. upon request, provide other Members with copies of the technical regulations;

3. without discrimination, allow other Members to present their comments in writing, discuss these comments upon request, and take these written comments and the results of these discussions into account. 
yang digunakan, sistem penilaian kesesuaian atau pengawasan yang digunakan. $^{34}$

Bentuk pengawasan dalam regulasi teknis dapat dibedakan menjadi dua mekanisme yaitu pengawasan pra pasar dan pengawasan pasar.

\subsubsection{Pengawasan Pra Pasar}

5.3.1.1. Pengawasan pra pasar merupakan mekanisme untuk menyatakan bahwa suatu barang dan/atau jasa memenuhi ketentuan yang tercantung dalam regulasi teknis sebelum diedarkan di pasat atau dioperasikan.

5.3.1.2. Inti dari pengawasan pra pasar adalah penilaian kesesuaian karakteristik barang dan/atau jasa terhadap ketentuan regulasi teknis.

5.3.1.3. Kesesuaian terhadap persyaratan regulasi teknis dapat menggunakan salah sau dari ketentuan berikut:

(1) Pernyataan kesesuaian dari produsen berdasarkan ISO/IEC 17050 Conformity Assesment- Supplier' declaration of conformity. ${ }^{35}$

(2) Penilaian Kesesuaian oleh LPK yang diregistrasi oleh instansi teknis setelah diakreditasi KAN untuk ruang lingkup akreditasi yang sesuai;

(3) Penilaian kesesuaian oleh LPK yang diregistrai oleh instansi teknis berdasarkan pengakuan dalam perjanjian saling keberterimaan antar

\footnotetext{
${ }^{34}$ Butir 8 Peraturan Kepala Badan Standarisasi Nasional Nomor 301 Tahun 2011 tentang Pedoman Pemberlakuan SNI secara wajib.

${ }^{35}$ ISO/IEC 17050-1:2004 specifies general requirements for a supplier's declaration of conformity in cases where it is desirable, or necessary, that conformity of an object to the specified requirements be attested, irrespective of the sector involved.
} 
LPK untuk ruang lingkup pengakuan yang sesuai; Catatan: dalam bidang elektronika dan kelistrikan mencakup skema penilaian kesesuaian yang dikembangkan oleh IEC.

(4) Pernyataan kesesuaian terhadap regulasi teknis negara lain yang terikat dengan perjanjian bilateral, regional maupun multilareral.

(5) Kesesuian terhadap keseluruhan atau sebagian paramater SNI yang dipersyaratkan dalam regulasi teknis dinyatakan dengan sertifikat kesesuaian dan/atau pembubuhan tanda kesesuaian yang di tetapkan oleh dalam PSN dan dirinci lebih lanjut dengan ketentuan KAN.

(6) Penentuan persyaratan dan tata cara pemberian sertifikat kesesuaian dan pembubuhan tanda kesesuaian dilakukan sesuai dengan kebutuhan dan tidak berlebihan agar tidak membebani produsen serta memperhatikan ketentuanketentuan sebagai berikut:

(a) Memenuhi ketentuan dalam PSN yang terkait dengan penilaian kesesuaian dan ketentuan KAN;

(b) Tidak membedakan penilaian kesesuaian yang diterapkan bagi produsen dalam negeri dan luar negeri;

(c) Tidak mendiskriminasikan penilaian kesesuaian yang diterapkan bagi barang dan/atau jasa dari suatu negara dengan barang dan atau jasa dari negara lain. ${ }^{36}$

\footnotetext{
${ }^{36} \mathrm{Hal}$ ini sesuai dengan ketentuan Article 2.1 TBT Agreement yang menyatakan Members shall ensure that in respect of technical regulations, product imported from the territory of any
} 
(7) Lembaga penilaian kesesuaian harus melakukan pemantauan dan pengawasan terhadap barang dan/atau jasa yang telah diberikan sertifikat olehnya untuk menjamin konsistensi pemenuhan persyaratan SNI, dan apabila tidak memenuhi persyaratan SNI maka lembaga penilaian kesesuaian harus melakukan tindakan koreksi termasuk pembekuan atau pencabutan sertifikat sesuai dengan PSN dan ketentuan KAN.

\subsubsection{Pengawasan Pasar}

(1) Pengawasan pasar merupakan mekanisme untuk mengawasai dan mengoreksi barang dan/atau jasa yang diedarkan di pasar atau dioperasikan untuk mengetahui kesesuaiannya dengan ketentuan regulasi teknis.

(2) Pengawasan pasar harus segera dilaksanakan setelah suatu regulasi teknis berlaku secara efektif, karena pada tingkat tertentu keberadaan pelaku usaha yang tidak bertanggung jawab dapat mengakibatkan timbulnya persaingan yang tidak sehat bagi pelaku usaha yang taat memenuhi ketentuan-ketentuan yang dipersyaratkan, serta menurunkan kewibawaan pemerintah.

(3) Pengawasan Pasar ditindaklanjuti dengan perbaikan, penarikan dari peredaran atau pemusnahan, terhadap barang dan/atau jasa yang tidak sesuai dengan regulasi teknis, dan apabila diperlukan pihak yang terkait dengan barang dan/atau jasa tersebut dapat

Member shall be accorded treatment no less favourable that accorded to like products of national origin and to like products originating in any other country. 
diberikan sanksi sesuai dengan peraturan perundangundangan yang berlaku.

(4) Pengawasan pasar merupakan tanggung jawab instansi teknis yang menetapkan regulasi dan pelaksanaanya dapat didelegeasikan kepada instansi teknis dan/atau pemerintah daerah sesuai dengan peraturan perundang-undangan yang berlaku. Pengawasan pasar untuk penerapan regulasi teknis dengan sistem tertentu dapat dilakukan menggunakan jasa dari lembaga penilaian kesesuaian yang telah diakreditasi oleh KAN untuk menggunakan tata cara dan ketentuan yang umum dipergunakan dalam mekanisme penilaian kesesuaian SNI karena hal tersebut dapat mengurangi timbulnya perbedaan penilaian yang dapat merugikan pelaku usaha.

(5) Dalam hal pengawasan pasar sangat mempengaruhi kepatuhan pihak yang terikat oleh suatu regulasi teknis, maka instansi teknis harus merencanakan dan melaksanakan pengawasan pasar secara efektif. ${ }^{37}$

Selanjutnya mengenai efektifitas regulasi teknis harus dievaluasi dan kaji ulang secara berkala paling lama 5 (lima) tahun sekali. Dalam hal kondisi atau tujuan yang melandasi regulasi teknis tersebut sudah tidak sesuai lagi, maka regulasi teknis tersebut harus dicabut agar tidak menimbulkan dampak negatif dalam perdagangan. ${ }^{38}$ Dalam hal

${ }^{37}$ Butir 8 dan Butir 9 Lampiran 1 Peraturan Kepala Badan Standarisasi Nasional Nomor 301 Tahun 2011 tentang Pedoman Pemberlakuan SNI secara wajib

38 Butir 10 Peraturan Kepala Badan Standarisasi Nasional Nomor 301 Tahun 2011 Tentang Pedoman Pemberlakuan SNI secara wajib dan Article 2.3 TBT Agreement yang menyatakan Technical regulations shall not be maintained if the circumstances or objectives giving rise to their adoption no longer exist or if the changed circumstances or objectives can be addressed in a less trade-restrictive manner. 
melakukan evaluasi dan kaji ulang suatu regulasi teknis perlu mempertimbangkan sejumlah aspek penting sebagai berikut:

5.3.1. Perubahan keadaan yang mengkibatkan tujuan pemberlakuan SNI secara wajib tidak sesuai lagi;

5.3.2. Tujuan pemberlakuan SNI secara wajib telah tercapai sehingga regulasi tersebut tidak diperlukan lagi atau dapat digantikan dengan cara yang lebih tidak mengikat;

5.3.3. Terjadi dampak yang tidak diantisipasi dan menimbulkan hambatan bagi perkembangan dunia usaha dan perdagangan;

5.3.4. Adanya revisi atau abolisi.

Agar SNI memperoleh keberterimaan yang luas antara pada Stakeholder maka SNI dirumuskan dengan memenuhi WTO Code of Good Practice, yaitu: ${ }^{39}$

\subsubsection{Openness.}

Terbuka bagi agar semua stakeholder yang berkepentingan dapat berpatisipasi dalam pengembangan SNI.

\subsubsection{Transparency.}

Transparan agar semua stakeholder yang berkepentingan dapat mengikuti perkembangan SNI mulai dari tahap pemprograman dan perumusan sampai ke tahap penetapannya. dan dapat dengan mudah memperoleh semua informasi yang berkaitan dengan pengembangan SNI.

\subsubsection{Consensus and impartiality.}

Tidak memihak dan konsensus agar semua stakeholder dapat menyalurkan kepentingannya dan diperlakukan secara adil.

5.3.4. Effectiveness and relevance.

Efektif dan relevan agar dapat memfasilitasi perdagangan karena memperhatikan kebutuhan pasar dan tidak

\footnotetext{
${ }^{39}$ http:www.bsn.go.id/sni/about_sni.php. Akses pada tangga 20 Juli 2018
} 
bertentangan dengan peraturan perundang-undangan yang berlaku.

\subsubsection{Coherence.}

Koheren dengan pengembangan standar Internasional agar perkembangan pasar negara tidak terisolasi dari perkembangan pasar global dan memperlancar perdagangan Internasional.

\subsubsection{Development dimension.}

Berdimensi pembangunan agar memperhatikan kepentingan publik dan kepentingan nasional dalam meningkatkan daya saing perekonomian nasional.

\section{Kesimpulan}

6.1. Di Indonesia perumusan SNI dilaksanakan oleh Badan Standardisasi Nasional (BSN), dalam melaksanakan perumusan SNI, BSN membetuk Komite Teknis, komite teknis terdiri atas unsur: (1). Pemerintah dan/atau Pemerintah Daerah. (2). Pelaku Usaha dan/atau asosiasi terkait. (3). Konsumen dan/atau asosiasi terkait serta (3). Pakar dan/atau akademisi. Kemudian melalui perumusan SNI membuat rancangan SNI yang ditetapkan menjadi SNI dengan keputusan kepala BSN. Berkaitan dengan penerapan SNI dilakukan dengan cara menerapkan persyaratan SNI terhadap barang, jasa, sistem, proses atau personal. Penerapan SNI dilaksanakan secara sukarela atau diberlakukan secara wajib. Penerapan SNI dibuktikan melalui pemilikan sertifikat dan/atau pembubuhan Tanda SNI dan/atau Tanda kesesuaian.

6.2. Untuk menyesuaikan dengan perkembangan penerapan standar serta pemberlakukan regulasi teknis berbasis standar di tingkat nasional, regional, dan internasional, dibutuhkan pedoman yang dapat dijadikan sebagai acuan. Oleh karena itu BSN menerbitkan Peraturan Kepala Badan Standardisasi Nasional Nomor 301 Tahun 2011 tentang Pedoman Pemberlakuan SNI secara wajib. Pedoman Standarisasi Nasional (PSN) 
ini merupakan pedoman bagi Instansi teknis dalam memberlakukan suatu regulasi teknis secara wajib yang berbasis SNI yang terkait dengan TBT Agreement, mencakup persiapan dan kajian pemberlakuan SNI secara wajib, program nasional regulasi teknis, perumusan regulasi teknis, notifikasi, penetapan, implementasi, pengawasan, evaluasi, dan kaji ulang regulasi teknis. Untuk perumusan lebih lanjut, rancangan regulasi teknis harus dinotifikasikan ke WTO sesuai dengan ketentuan dalam perjanjian TBT-WTO, notifikasi dilakukan melalui BSN sebagai Notification body dan enquiry point, notifikasi harus dilaksanakan paling singkat enam puluh (60) hari sebelum regulasi teknis ditetapkan untuk memberikan kesempatan kepada pihak berkepentingan didalam dan luar negeri untuk memberikan masukan dan tanggapan sesuai dengan ketentuan TBT-WTO, dalam hal regulasti teknis berkaitan dengan keamanan, keselamatan, kesehatan, serta pelestarian fungsi lingkungan hidup atau keamanan negara harus segera diatasi, ketentuan tersebut dapat diabaikan dengan catatan bahwa regulasi teknis tersebut harus segera dinotifikasi ke WTO, paling lama 1 (satu) bulan setelah ditetapkan. 


\section{DAFTAR PUSTAKA}

\section{Buku}

Hata. Perdagangan Internasional Dalam Sistem GATT dan WTO Aspek-Aspek Hukum Dan Non Hukum. Jakarta: Refika Aditama, 2006.

Huala Adolf. Hukum Perdagangan Internasional. Jakarta: PT. Raja Grafindo Persada, 2013.

Joseph E. Stiglitz and Andrew Charlton. Fair Trade For All How Trade Can Promote Development. New York: Oxford University Press inc, 2005.

Karina Imasepti, Darminto Hartono Paulus, \& Joko Priyono. "Implementasi Technical Barrierss To Trade Agreement Dalam Kasus Pemberian Label 'Warning' Pada Produk PT. Sido Muncul." Diponegoro Law Review 5, no. 2 (2016).

Michael J. Trebilcock and Robert Howse. The Regulations of Internasional Trade Second Edition. London: Routledge, 1999.

Michaels Koebele \& Max Planck. Commentaries on World Trade Law Volume. Leaden: Koninklijke Brill NV, 2007.

Mitsuo Matsushita, Thomas J. Schoenbaum \& Petros C. Mavroidis. The World Trade Organization Law, Practice and Policy. United States: Oxford University Press inc, 206AD.

Muhamaad Sood. Hukum Perdagangan Internasional. Jakarta: PT. Raja Grafindo Persada, 2011.

Mukti Fajar ND dan Yulianto Achmad. Dualisme Penelitian Hukum Normatif \& Empiris. Yogyakarta: Pustaka Pelajar, 2010. 


\section{Artikel Jurnal}

Darminto Hartono Paulus, Fx. Joko Priyono, Karina Imasepti. "Implementasi Technical Barriers to Trade Agreement dalam Kasus Pemberian Label 'Warning' Pada Produk PT. Sido Muncul.” Diponegoro Law Review 5, no. 2 (2016).

Nandang Sutrisno. "Efektifitas Ketentuan-Ketentuan World Trade Organization tentang Perlakuan Khusus dan Berbeda Bagi Negara Berkembang: Implementasi Dalam Praktek dan Dalam Penyelesaian Sengekta.” Jurnal Hukum Ius Quia Iustum 16, no. Edisi Khusus (2009).

Syukri Hidayatullah. "Perbandingan Hukum Pengaturan Standardisasi Menurut Agreement TBT dan Undang-Undang No.7 Tahun 2014 tentang Perdagangan." Arena Hukum 9, no. 2 (2016).

\section{Peraturan Perundang-Undangan}

General Agreement on Tariffs and Trade (GATT)

Technical Barriers To Trade Agreeement (TBT Agreement)

Sanitary Phytosanitary Measures Agreement (SPS Agreement)

Titie 27 California Code Regulation, Pasal 25306

Undang-Undang No. 20 Tahun 2014 tentang Standardisasi Produk dan Penilaian Kesesuaian

Peraturan Pemerintah Republik Indonesia Nomor 55 Tahun 2012 tentang Kendaraan

Peraturan Menteri Pertanian Nomor 58 Tahun 2007 tentang Pelaksanaan Sistem Standardisasi Nasional di Bidang Pertanian

Peraturan Kepala Badan Standarisasi Nasional Nomor 301 Tahun 2011 tentang Pedoman Pemberlakuan SNI secara wajib

\section{Media Online}

http://www.bsn.go.id/main/bsn/isi_bsn/20166/penerapan-sni Http:www.bsn.go.id/sni/about_sni.php. 